\title{
The marvels of elite sports: how to get there?
}

\author{
Marije T Elferink-Gemser, ${ }^{1,2}$ Geir Jordet, ${ }^{3}$ \\ Manuel J Coelho-E-Silva, ${ }^{4}$ Chris Visscher ${ }^{1}$
}

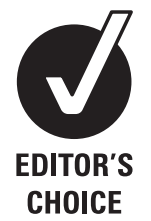

Elite athletes' performances are astonishing, leaving millions of people wondering how it is possible that they do what they do. With apparent ease, grace and fluidity, elite athletes carry out seemingly impossible manoeuvres. They constantly push the boundaries of human performance and we, the ones standing on the sideline, are fascinated by it. In contemporary Western society, sport is part of our everyday lives with elite sport having become a multi-million euro business. While sport is probably the major opportunity of physical activity for all children and adolescents, elite athletes are considered role models for many of them.

If we look under the surface of elite sport, we know that every elite athlete was once a child and has gone a long way before reaching the top. What characterised their successful development towards expertise? One way to gain insight into this intriguing question is to simply ask current elite athletes to retrospectively report what they have done. They would probably tell you that they have dedicated most of their time, energy, resources and effort, with the goal of becoming the best that they can be. ${ }^{1}$ Still, this leaves us with the question of how to identify and develop those youth athletes who have the potential to become outstanding when they are older. The prediction of long-term success is extremely difficult and the later successful athletes are not necessarily the

${ }^{1}$ Center for Human Movement Sciences, University Medical Center Groningen, University of Groningen, Groningen, The Netherlands

2Institute for Studies in Sports and Exercise, HAN University of Applied Sciences, Nijmegen, The Netherlands

${ }^{3}$ Department of Coaching and Psychology, Norwegian School of Sport Sciences, Oslo, Norway

${ }^{4}$ Department of Sport Science and Physical Education, University of Coimbra, Coimbra, Portugal

Correspondence to Marije T Elferink-Gemser, Center for Human Movement Sciences, University Medical Center Groningen, University of Groningen, 9713 AV Groningen, The Netherlands;

m.t.elferink-gemser@med.umcg.nl ones who performed best in youth competitions. $^{2}{ }^{3}$ The reason for this is that many factors play a role; factors related to both the athlete (ie, rate of learning, training and maturation of anthropometric, physiological, technical, tactical and psychological skills) and the environment (ie, opportunities created by parents, trainers, coaches, talent development programme and the competition structure) along with a component of chance. ${ }^{4}$ For example, we know that body size is related to sports performance and that youth athletes with more advanced levels of maturity (sexual, skeletal, age at peak height velocity) are, on average, taller than peers who are more delayed in maturity status. ${ }^{5}$ Therefore, in youth sport competitions, the more mature athletes seem to perform better. ${ }^{6}$ This, however, is only a temporary advantage because when adolescence nears termination, height differences among athletes of contrasting maturity status are negligible. ${ }^{7}$

An often cited 'rule of the thumb' is that in order to reach expertise, at least 10000 $\mathrm{h}$ of deliberate practice in a period of 10 years is needed. ${ }^{8}$ This means that talent identification and development in most sports may take place during athletes' adolescent growth spurt. Studies on the relative age effect ${ }^{9}$ support the notion that in reality many youth athletes are still identified as being talented on the basis of their current rather than their future level of performance and, consequently, the best youth performers are the ones who are invited to join talent development programmes or selection teams. This implies that in our talent identification system, we systematically and mistakenly fail to notice the talented athletes who may not be the best performers yet, but who have the potential to be so in the future. Moreover, we fail to provide this neglected group of athletes with extra training facilities, highly certified trainers and medical supervision. Therefore, to further unravel the mystery of talent, the best way may be to longitudinally follow youth athletes throughout their sports career, from start to adulthood, measuring underlying multidimensional factors and characteristics, and track their levels of performance in the hope that some of these athletes will make it to the top. ${ }^{10-12}$

In the last decade, over a 1000 talent identified athletes in a variety of sports, among which are soccer players, field hockey players, basketball players, artistic gymnasts, tennis players and speed skaters, have been followed up in the Groningen talent studies. ${ }^{13}$ These studies revealed that to reach expertise, athletes have their own unique development patterns. For example, although on average the ultimately successful soccer players (ie, the ones signing a professional contract) seem to have acquired better dribbling skills by the age of $14,{ }^{14}$ developed their interval endurance capacity faster from the age of $15,{ }^{15}$ and outscored later amateurs by their tactical skills at the age of $17,{ }^{16}$ individual developmental curves differ from each other. This is in line with recent recommendations to eschew the notion of common optimal performance development and instead emphasise the individual nature of pathways to expertise. ${ }^{17}$

Still, several studies clearly show that what future successful athletes do have in common is their capability to, more than others, derive more from the same number of practice hours, and, as a consequence, they are better able to constantly improve their performance. ${ }^{18-21}$ They are known to take responsibility for the progress they make and score higher on aspects of selfregulation of learning, such as reflection and effort. $^{22} 23$ This means that they may set goals that are more realistic and more clear, be more aware of their strong and weak points and be more willing to put effort into training and competition. With world records being broken regularly, youth athletes attempting to make it to the top need to be aware of the increasing demands of their sports and what it takes for them to be the new Arjen Robben or Kim Clijsters. In sports, there is only restricted time available to perform at the elite level due to processes of ageing causing decreasing performance, making it even more important to improve as much from training and competition as possible. In other words, with such small windows of opportunity, youth athletes need to take responsibility for their own development process and direct their attention to the quality of their training even more than to the quantity of it. We can help by providing a challenging environment to those youth athletes who devote their lives in pursuit of the dream of becoming the best they can be, 
but not by excluding youth based on their current level of performance. Rather, we need to focus on youth athletes' potential to develop towards expertise in the future. By tracking their learning, training and maturation related to their personal performance characteristics (ie, anthropometric, physiological, technical, tactical and psychological), we can more effectively guide them towards their goal.

Accepted 24 May 2011

Br J Sports Med 2011;45:683-684.

doi:10.1136/bjsports-2011-090254

\section{REFERENCES}

1. Starkes JL. The magic and the science of sport expertise. In Starkes JL, Ericsson KA, eds. Expert Performance in Sports. Advances in Research on Sport Expertise. Leeds: Human Kinetics, 2003:3-15.

2. Abbott A, Button C, Pepping GJ, et al. Unnatural selection: talent identification and development in sport. Nonlinear Dynam Psychol Life Sci 2005;9:61-81.

3. Howe MJ, Davidson JW, Sloboda JA. Innate talents: reality or myth? Behav Brain Sci 1998;21:399-407; discussion 407-42.

4. Elferink-Gemser MT, Visscher C. Who are the superstars of tomorrow? Talent development in Dutch soccer. In: Baker J, Schorer J, Cobley S, eds. Talent identification and development in sport. International perspectives. London: Routledge (In press).

5. Coelho E Silva MJ, Moreira Carvalho $\mathrm{H}$, Goncalves CE, et al. Growth, maturation, functional capacities and sport-specific skills in 12-13-yearold-basketball players. J Sports Med Phys Fitness 2010;50:174-81.

6. Figueiredo AJ, Gonçalves CE, Coelho E Silva MJ, et al. Characteristics of youth soccer players who drop out, persist or move up. J Sports Sci 2009;27:883-91.

7. Malina RM, Cumming SP, Morano PJ, et al. Maturity status of youth football players: a noninvasive estimate. Med Sci Sports Exerc 2005;37:1044-52.

8. Ericsson KA. The Road to Expert Performance: Empirical Evidence from the Arts and Sciences, Sports, and Games. Mahwah, NJ: Erlbaum, 1996.

9. Helsen WF, van Winckel J, Williams AM. The relative age effect in youth soccer across Europe. J Sports Sci 2005;23:629-36.

10. Elferink-Gemser MT, Visscher C, Lemmink KAPM, et al. Relation between multidimensional performance characteristics and level of performance in talented youth field hockey players. J Sports Sci 2004;22:1053-63.

11. Elferink-Gemser MT, Visscher C, Lemmink KA, et al. Multidimensional performance characteristics and standard of performance in talented youth field hockey players: a longitudinal study. J Sports Sci 2007;25:481-9.

12. Vaeyens R, Malina RM, Janssens M, et al. A multidisciplinary selection model for youth soccer: the Ghent Youth Soccer Project. Br J Sports Med 2006;40:928-34.

13. Elferink-Gemser MT, Visscher $C$, van Duijn MA, et al. Development of the interval endurance capacity in elite and sub-elite youth field hockey players. Br J Sports Med 2006;40:340-5.

14. Huijgen BC, Elferink-Gemser MT, Post WJ, et al. Soccer skill development in professionals. Int J Sports Med 2009;30:585-91.
15. Roescher CR, Elferink-Gemser MT, Huijgen BC, et al. Soccer endurance development in professionals. Int J Sports Med 2010;31:174-9.

16. Kannekens R, Elferink-Gemser MT, Visscher C. Positioning and deciding: key factors for talent development in soccer. Scand J Med Sci Sports 2010 (In press)

17. Phillips E, Davids K, Renshaw I, et al. Expert performance in sport and the dynamics of talent development. Sports Med 2010;40:271-83.

18. Cleary TJ, Zimmerman BJ. Selfregulation differences during athletic practice by experts, non-experts, and novices. J App/ Sport Psy 2001;13:185-206.

19. Ertmer PA, Newby TJ. The expert learner: Strategic, self-regulated, and reflective. Instructional Science 1996;24:1-24.

20. Jonker L, Elferink-Gemser MT, Visscher. Differences in self-regulatory skills among talented athletes: the significance of competitive level and type of sport. J Sports Sci 2010;28:901-8.

21. Zimmerman BJ, Ericsson KA, Charness $\mathrm{N}$, et al. Development and adaptation of expertise: The role of self-regulatory processes and beliefs. In: Ericsson KA, Charness N, Feltovich PJ, Hoffman RR, eds. The Cambridge Handbook of Expertise and Expert Performance. New York: Cambridge University Press, 2006:705-22.

22. Jonker L, Elferink-Gemser MT, Toering $\mathrm{TT}$, et al. Academic performance and self-regulatory skills in elite youth soccer players. J Sports Sci 2010;28:1605-14

23. Toering TT, Elferink-Gemser MT, Jordet G, et al. Self-regulation and performance level of elite and non-elite youth soccer players. J Sports Sci 2009;27:1509-17. 